\title{
Micelas reversas de lecitina de soja - uma alternativa para purificação de proteínas
}

\author{
Francislene Andréia Hasmann*1,3, Daniela Vieira Cortez', Daniela de Borba Gurpilhares', Inês \\ Conceição Roberto ${ }^{1}$, Adalberto Pessoa Júnior ${ }^{2,3}$
}

${ }^{1}$ Departamento de Biotecnologia, Escola de Engenharia de Lorena, Universidade de São Paulo, ${ }^{2}$ Departamento de Tecnologia Bioquímico Farmacêutica, Faculdade de Ciências Farmacêuticas, Universidade de São Paulo, ${ }^{3} I P T$,

Butantan, Universidade de São Paulo

*Correspondência:

F. A. Hasmann

Departamento de Biotecnologia

Escola de Engenharia de Lorena - USP

Estrada Municipal do Campinho, s/n

Caixa Postal 116

12602-810 - Lorena - SP, Brasil

E-mail: francislene@debiq.eel.usp.br

\begin{abstract}
No presente trabalho, estudaram-se os efeitos de diversos parâmetros sobre a extração das proteinas caseína e albumina de soro bovino empregando micelas reversas de lecitina de soja. Independentemente da condição empregada, a extração da albumina apresentou baixo rendimento (variando de $0 \%$ a 4\%, aproximadamente), resultado de um significativo efeito de exclusão por tamanho. Com relação à caseína, o rendimento da extração aumentou 23 vezes com o aumento do tempo de agitação, ou seja, com o maior tempo de contato entre a proteina e o sistema de micelas reversas. A adição de 1-hexanol ao sistema, usado como co-solvente, foi efetiva, aumentando a solubilização da caseína em $36 \%$, sendo os rendimentos da extração desta proteína muito influenciados pelo $\mathrm{pH}$. Os valores máximos de eficiência obtidos foram de $20 \%$ em pH 7,9, 80\% em pH 5,4 e 100\% em pH 5,0 (pH próximo ao pI da proteína).
\end{abstract}

\author{
Unitermos \\ - Micelas reversas \\ - Lecitina de soja \\ - Extração líquido-líquido \\ - Caseína \\ - Albumina de soro bovino \\ - Proteínas/purificação
}

\section{INTRODUÇÃO}

O aprimoramento de operações unitárias aplicadas em bioprocessos e bioprodutos, as chamadas de técnicas de "downstream processing", se faz necessário para atender a demanda de pesquisas na área de biotecnologia. Existem inúmeros estudos de purificação de uma grande variedade de substâncias. No entanto, tais estudos empregam principalmente técnicas cromatográficas (Yüregir et al., 1994; Özer, 2002; Çiftçi et al., 2003).

Nos últimos anos, a solubilização de componentes biologicamente ativos em sistemas micelares reversos tais como aminoácidos (Furusaki et al., 1990), peptídeos (Leodidis e Hatton, 1990), proteínas (Hasmann et al., 2001) entre outros, tem sido amplamente estudada. A aplicação da extração por micelas reversas trata-se de uma ampliação da técnica de separação através da tradicional extração por solventes. Esta técnica apresenta vantagens operacionais como possibilidade de extração em sistema contínuo e ampliação de escala. Esses sistemas oferecem ainda, vantagens como possuírem poucas limitações à transferência de massa, grande área interfacial e aumento da atividade catalítica (Ichikawa et al., 2000). Sistemas micelares reversos vêm sendo empregados na purificação de enzimas, como a betaxilosidase e a xilanases (Hasmann et al., 1999; Cortez e Pessoa, 1999), além de serem utilizados no encapsulamento de enzimas empregadas na bioconversão de substratos hidrofóbicos como os lipídeos (Morita et al., 1984). 
Estudos recentes da purificação de produtos biotecnológicos, tais como enzimas e proteínas, por micelas reversas demonstram o interesse científico na utilização desta técnica (Kilikian et al., 2000; Hasmann et al., 2007). A recuperação de proteínas de um meio aquoso usando a extração líquido-líquido por micelas reversas é, em princípio, um método promissor (Rodrigues et al., 1999; Hasmann et al., 2003).

Micelas reversas são formações espontâneas e reversíveis de agregados esféricos de moléculas anfifílicas em solução apolar. Na presença de água solubilizada, os centros aquosos presentes nestes agregados são capazes de solubilizar enzimas e outras substâncias, promovendo sua purificação (Rodrigues et al., 1999). Embora a capacidade de extração de sistemas micelares reversos formadas por tensoativos iônicos (como o aerossol OT-AOT, brometo de cetil trimetil amônio-CTAB, entre outros) tenha sido comprovada para várias biomoléculas, a presença de traços destes tensoativos no produto final gera limitações para a aplicação da técnica em "downstream processing”, pois estes tensoativos podem, por exemplo, causar a desnaturação de proteínas (Pires et al., 1996; Hasmann et al., 2003). Desta forma, o uso de tensoativos zwiteriônicos na formação de micelas reversas, em substituição aos iônicos, apresenta-se como alternativa para a utilização da técnica (Pinto-Sousa et al., 1996; Sun et al., 1999). Dentre os tensoativos zwiteriônicos merece destaque a lecitina de soja (LS), amplamente utilizada como aditivo em alimentos. Os principais componentes da LS são fosfolipídeos como a fosfatidilcolina e fosfatidiletanolamina (Smith et al., 1993).

Vários parâmetros, como: tipo e tempo de agitação, tipo e concentração do co-solvente, $\mathrm{pH}$, tipo e concentração do tensoativo, condutividade elétrica, temperatura e introdução de ligantes à estrutura das micelas reversas são importantes aos processos de extração por micelas reversas. Tais parâmetros interferem nos resultados do processo e devem ser estudados visando obter melhores desempenhos no uso de sistemas micelares reversos.

Neste trabalho, os seguintes parâmetros reconhecidamente importantes na extração de proteínas por micelas reversas foram avaliados: tipo e tempo de agitação, concentração do co-solvente, $\mathrm{pH}$ e introdução do ligante CibacronBlue à estrutura das micelas reversas de LS.

\section{MATERIAL E MÉTODOS}

\section{Materiais}

Caseína, albumina de soro bovino (BSA) e lecitina de soja (fosfatidilcolina de soja a 99,9\%) foram adquiridos da Sigma ${ }^{\circledR}$. Os solventes isooctano (2,2,4-trimetilpentano) e 1-hexanol da marca Merck ${ }^{\circledR}$. Os demais reagentes possuíam grau analítico. Os reagentes foram usados como recebidos.

\section{Extração por Micelas Reversas}

Utilizou-se o sistema micelar formado pelo tensoativo zwiteriônico lecitina de soja $(0,05 \mathrm{M} \mathrm{e} 0,1 \mathrm{M})$ em isooctano com 1-hexanol a $25 \mathrm{mM}$. Para a realização do processo de extração, a fase aquosa inicial contendo proteína (BSA ou caseína) e o sistema micelar reverso (tensoativo e solventes) foram misturados em partes iguais empregando-se agitação orbital (Ética Mod. 4500) ou agitador tipo vórtice (Phoenix Mod. AP56); empregando temperatura ambiente $\left(25 \pm 1{ }^{\circ} \mathrm{C}\right)$. Após agitação a mistura foi centrifugada (Centrífuga Jouan Mod.1812, Saint Herblain) a $1677 x g$ por 10 min e $25^{\circ} \mathrm{C}$ para separação de duas novas fases: uma fase aquosa (FA1) e uma fase micelar (FM1)

Para o desenvolvimento do processo de extração empregando agitação em vórtice, o procedimento foi idêntico ao utilizado na extração empregando agitação orbital com a substituição do agitador.

\section{Determinação do Teor de Proteínas Totais}

O teor de proteínas totais foi determinado de acordo com o método de Lowry et al. (1959), utilizando como padrão albumina de soro bovino (BSA). As proteínas totais foram dosadas na fase aquosa inicial e na FA1, empregando espectofotômetro (Beckman DU 6408).

\section{RESULTADOS E DISCUSSÃO}

No presente trabalho, estudou-se um sistema de micelas reversas formado por tensoativo biocompatível devido à necessidade de desenvolvimento e aplicação de novas técnicas biotecnólogicas que reflitam em benefícios e/ou menor agressão ao ambiente. Assim, os sistemas cujos componentes (ou parte) sejam biocompatíveis devem ter seu estudo aprofundado. Com o presente trabalho, buscouse aumentar as informações sobre os sistemas micelares reversos formados com este tensoativo e ampliar as possibilidades de utilização na purificação de outras biomoléculas de interesse.

Para a avaliação da influência da condutividade e do tipo de agitação sobre o processo de extração por micelas reversas de lecitina de soja $(0,05$ e $0,10 \mathrm{M}$ com $25 \mathrm{mM}$ de 1-hexanol em isooctano), utilizou-se como fase aquosa inicial uma solução salina ( $\mathrm{NaCl}$ em água) de modo a se obter diferentes valores de condutividade elétrica $(3,6,10$, 15 e $20 \mathrm{mS} / \mathrm{cm}^{2}$, respectivamente $0 ; 0,2 ; 0,4 ; 0,5$ e 
$0,6 \mathrm{~mol} / \mathrm{L}$ ) e observar os efeitos da salinidade da fase aquosa sobre o processo de extração.

Os resultados obtidos demonstraram que o uso da agitação em vórtice para o presente sistema é inviável, uma vez que pode ocorrer a emulsificação de uma das fases aquosas, independentemente da concentração do tensoativo, tempo de agitação e condutividade elétrica utilizada. Estes sistemas emulsionados foram deixados em repouso com o intuito de se averiguar a ocorrência de nova separação de fases, entretanto decorridas mais de 20 horas (overnight) tal fato não foi observado.

Diferentemente, quando se empregou agitação orbital não foi observada emulsificação dos sistemas sob nenhuma das condições avaliadas, indicando a viabilidade de seu uso.

Com o intuito de se analisar a influência de diferentes parâmetros sobre o processo de extração por micelas reversas do tensoativo lecitina de soja foram utilizadas soluções contendo as proteínas albumina de soro bovino (BSA) e caseína.

BSA é tradicionalmente purificado por técnicas cromatográficas, membranas e/ou precipitação (Rautenbach, Albrecht, 1989; Vançan, 1999, Hwang, Hwang, 2006). No entanto, no presente trabalho, empregou-se a extração líquido-líquido por micelas reversas, utilizando LS num sistema ainda não avaliado pela literatura.

Nos estudos com BSA empregou-se como fase aquosa solução desta proteína em tampão tris/ $\mathrm{HCl} 0,05 \mathrm{M} \mathrm{pH}$ 7,8 , e como fase micelar, uma microemulsão formada por lecitina de soja nas concentrações de $0,05 \mathrm{M} \mathrm{e} 0,1 \mathrm{M}$ com 1-hexanol $25 \mathrm{mM}$ em isooctano. Nestes estudos foi empregada BSA devido sua quantificação ser realizada empregando-se o método desenvolvido por Lowry e colaboradores (1959), poupando reagentes empregados na determinação de atividades enzimáticas, e devido ao conhecimento da massa molar e seu pI da proteína, $64 \mathrm{kDa}$ e 4,7, respectivamente. (Sun et al., 1999).

Numa primeira etapa estudou-se o efeito do tempo de agitação (em agitador orbital a $280 \mathrm{rpm}$ ) sobre a extração da proteína BSA da solução inicial (SI) para a fase micelar. A extração foi conduzida a $25^{\circ} \mathrm{C}$ e a centrifugação foi realizada sob as mesmas condições de temperatura, 1600xg por 10 minutos. Os tempos de agitação estudados foram de $1,10,30,45$ e 60 minutos. Esta quantificação foi feita com base num balanço de massa para a proteína da FAI, observando-se o rendimento em extração do sistema $(\mathrm{R} \%)$. Para tanto, as proteínas foram quantificadas antes (controle) e após a etapa de extração.

Os resultados apresentados na Tabela I mostram que o sistema não foi capaz de extrair BSA nas condições pro- postas, visto que os valores de rendimento ( $\mathrm{R} \%)$ são nulos ou estão dentro do erro experimental.

TABELA I - Rendimento (R \%) da extração de BSA na FAI por micelas reversas, utilizando um sistema lecitina de soja 0,05 M com 1-hexanol $25 \mathrm{mM}$ em isooctano

\begin{tabular}{ccc}
\hline Tempo $(\mathrm{min})$ & {$[\mathrm{BSA}](\mathrm{mg} / \mathrm{mL})$} & $\mathrm{R}(\%)$ \\
\hline $\mathbf{1}$ & 679,6 & 2,83 \\
$\mathbf{1 0}$ & 691,42 & 0,00 \\
$\mathbf{3 0}$ & 684,46 & 2,14 \\
$\mathbf{4 5}$ & 702,19 & 0,00 \\
$\mathbf{6 0}$ & 668,47 & 4,42 \\
\hline
\end{tabular}

Erro experimental $=5 \%-[\mathrm{BSA}]_{\text {controle }}=699,4 \mathrm{mg} / \mathrm{mL}$

Com base nos baixos rendimentos obtidos, novos ensaios foram conduzidos com o aumento da concentração de LS para $0,1 \mathrm{M}$ (com 1-hexanol $25 \mathrm{mM}$ em isooctano) adicionado ou não de Cibracon-blue (CB) na concentração de 0,1mM. De acordo com Sun et al. (1999), este aditivo promoveu um aumento de até 10 vezes na eficiência de englobamento de lipase por micelas reversas de LS.

Os rendimentos da etapa de extração foram quantificados e os resultados obtidos constam da Tabela II. Verifica-se que a apesar do aumento da concentração de tensoativo (LS) e do uso de CB como ligante, os valores de ( $\mathrm{R} \%$ ) foram nulos ou então contidos pelo erro experimental.

TABELA II - Rendimento (R \%) da extração de BSA por micelas reversas, utilizando um sistema lecitina de soja 0,1 $\mathrm{M}$ com 1-hexanol $25 \mathrm{mM}$ em isooctano, com e sem a presença de $\mathrm{CB}$ (cibracon-blue $0,1 \mathrm{mM}$ )

\begin{tabular}{lcccc}
\hline & \multicolumn{2}{c}{ Sem CB } & \multicolumn{2}{c}{ Com CB } \\
$\begin{array}{l}\text { Tempo } \\
(\mathrm{min})\end{array}$ & $\begin{array}{c}{[\mathrm{BSA}]} \\
(\mathrm{mg} / \mathrm{mL})\end{array}$ & $\mathrm{R}(\%)$ & {$[\mathrm{BSA}]$} & $\mathrm{R}(\%)$ \\
\hline $\mathbf{1}$ & 580,87 & 1,99 & 709,49 & 0 \\
$\mathbf{1 5}$ & 572,54 & 1,03 & 695,59 & 0 \\
$\mathbf{3 0}$ & 652,48 & 0,00 & 711,58 & 0 \\
$\mathbf{6 0}$ & 693,5 & 0,00 & 714,36 & 0 \\
\hline
\end{tabular}

Erro experimental $=5 \%-[\mathrm{BSA}]_{\text {controle }}=592,13 \mathrm{mg} / \mathrm{mL}$

De fato, consta da literatura que o aumento da concentração de tensoativo formador de micelas reversas neste sistema não resulta necessariamente no aumento do raio micelar. O aumento no parâmetro Wo (o qual exprime a relação molar entre a água quantificada e a concentração de tensoativo empregada) a partir do qual o raio micelar é 
matematicamente calculado por 1,64. Wo (Hasmann et al. 2001; Cortez et al., 2004), pode ser resultado do aumento do número de micelas reversas na microemulsão e não do tamanho destas, semelhante aos resultados de Gupte et al. (1995) e Hasmann (2000). Por este motivo o aumento da concentração de lecitina pode não ter proporcionado o efeito esperado.

Nos ensaios conduzidos com a presença de CB, a extração da proteína não apresentou resultados satisfatórios. Os valores quantificados após cada ensaio de extração foram maiores que os encontrada na amostra inicial. Tais resultados demonstram a existência de um erro experimental não passível de controle.

A escolha da metodologia de preparo e tipo de ligante utilizado foi baseada em resultados de Sun et al. (1999) que, utilizando um método de imobilização de CB diretamente na estrutura de micelas reversas de LS (em hexano), obtiveram um aumento significativo na solubilização de citocromo c e lisozima, resultante de um aumento nas forças de interação eletrostáticas entre proteínas e micelas reversas.

Segundo estes autores, entretanto, a extração de BSA por micelas reversas de LS resultou em baixo rendimento devido à relação desfavorável entre a massa molar desta proteína e o raio interno das micelas reversas, resultado de um significante efeito de exclusão por tamanho. Estes autores observaram que mesmo com a variação do $\mathrm{pH}$ de extração de 4,9 a 8,0 , um aumento de $6 \%$ a no máximo $12 \%$ no rendimento da extração de BSA foi obtido. Com base nestes resultados, os autores concluíram que micelas reversas de LS não são capazes de englobar proteínas com massa molar como a da BSA. Conclusões semelhantes são reportadas por outros autores que estudaram sistemas de micelas reversas formadas por LS (Yurtov e Murashova, 2003; Hasmann et al., 2007).

No presente trabalho, os rendimentos de extração de BSA foram nulos, e uma vez que a literatura apresenta resultados positivos para extração de biomoléculas empregando micelas reversas de LS, novos ensaios foram conduzidos utilizando caseína, cuja massa molar é $24 \mathrm{kDa}$, ou seja, inferior a do BSA.

Empregando o sistema micelar reverso LS a 0,05 e 0,1M (com 1-hexanol $25 \mathrm{mM}$ em isooctano), ensaios de extração da caseína foram conduzidos, sendo a fase aquosa inicial constituída de caseína em tampão tris/ $\mathrm{HCl} 0,05 \mathrm{M}$ $\mathrm{pH} 7,8$.

A extração foi conduzida a $25^{\circ} \mathrm{C}$, em agitador orbital (shaker) a 280 rpm variando-se os tempos de agitação de 1 , 15,30 e 60 minutos. Após as extrações empregando os tempos de agitação acima descritos, a amostra foi centrifugada à $1600 \mathrm{xg}$ por 10 minutos. $\mathrm{O}$ rendimento do processo foi quantificado como anteriormente definido, em termos da porcentagem de proteínas extraídas (balanço de massa).

Como pode ser observado na Tabela III, o rendimento de extração da caseína atingiu cerca de $15 \%$ para 60 minutos de agitação utilizando LS 0,1M e 19\% para 30 minutos de agitação com LS 0,05M. Apesar de modesto o rendimento, o sistema mostrou-se capaz de extrair caseína indicando ser, além das características de hidrofobicidade, a massa molar da proteína um dos prováveis fatores limitantes do processo.

TABELA III - Estudo do rendimento (R\%) da extração de caseína por micelas reversas, utilizando um sistema lecitina de soja $0,05 \mathrm{M}$ e $0,1 \mathrm{M}$ em isooctano, com 1-hexanol $25 \mathrm{mM}$

\begin{tabular}{|c|c|c|c|c|}
\hline \multirow[b]{2}{*}{$\begin{array}{l}\text { Tempo } \\
\text { (min) }\end{array}$} & \multicolumn{2}{|c|}{ Lecitina de soja $0,05 \mathrm{M}^{*}$} & \multicolumn{2}{|c|}{ Lecitina de soja $0,1 \mathrm{M}^{*}$} \\
\hline & $\begin{array}{c}\text { Caseína } \\
(\mathrm{mg} / \mathrm{mL})\end{array}$ & $\mathrm{R}(\%)$ & $\begin{array}{l}\text { Caseína } \\
(\mathrm{mg} / \mathrm{mL})\end{array}$ & $\mathrm{R}(\%)$ \\
\hline 1 & 478,66 & 0,00 & 465,45 & 0,00 \\
\hline 15 & 367,76 & 15,43 & 385,84 & 11,27 \\
\hline 30 & 352,46 & 18,95 & 382,01 & 12,15 \\
\hline 60 & 361,15 & 16,95 & 368,11 & 15,35 \\
\hline
\end{tabular}

[caseína $_{\text {controle }}=434,86(\mathrm{mg} / \mathrm{mL}) ; *$ Solução em isooctano com $25 \mathrm{mM}$ de 1-hexanol

Sun et al. (1999) obtiveram cerca de 98\% de rendimento de extração de lisozima $(14,3 \mathrm{kDa})$ num sistema composto por micelas de LS-Cibracon blue em hexano com mais de $0,5 \%$ de 1 -hexanol $(\mathrm{v} / \mathrm{v})$.

Paralelamente foram realizados, sob estas condições, ensaios de extração utilizando como forma de agitação o vórtice por 1, 5 e 10 minutos. Observou-se, novamente, em todos os ensaios em vórtice a emulsificação do sistema e, portanto, não puderam ser quantificados os rendimentos do processo.

$\mathrm{Na}$ etapa seguinte, os ensaios foram conduzidos a $25{ }^{\circ} \mathrm{C}$, em agitador orbital (shaker) a $280 \mathrm{rpm}$, porém o tempo de agitação foi aumentado até 120 minutos. Os resultados (conforme observado na Tabela IV) atingiram cerca de $20 \%$ com o uso de LS a $0,05 \mathrm{M}$ e $10 \%$ com LS a $0,1 \mathrm{M}$.

Utilizando LS $0,1 \mathrm{M}$ os rendimentos permaneceram constantes, indicando que o aumento do tempo de agitação não foi suficiente para aumentar os rendimentos da etapa de extração. Com a LS 0,05 M a eficiência da etapa de extração aumenta apenas $3 \%$ de 90 para 120 minutos. Desta forma, selecionou-se o tempo de agitação 60 minutos para realização dos ensaios, pois para este tempo ob- 
TABELA IV - Estudo do rendimento (R\%) da extração de caseína por micelas reversas, utilizando um sistema lecitina de soja $0,05 \mathrm{M}$ e $0,1 \mathrm{M}$ em isooctano, com 1-hexanol $25 \mathrm{mM}$

\begin{tabular}{|c|c|c|c|c|}
\hline \multirow[b]{2}{*}{$\begin{array}{l}\text { Tempo } \\
\text { (min) }\end{array}$} & \multicolumn{2}{|c|}{ Lecitina de soja $0,05 \mathrm{M}$} & \multicolumn{2}{|c|}{ Lecitina de soja $0,1 \mathrm{M}^{*}$} \\
\hline & $\begin{array}{c}\text { Caseína } \\
(\mathrm{mg} / \mathrm{mL})\end{array}$ & $\mathrm{R}(\%)$ & $\begin{array}{c}\text { Caseína } \\
(\mathrm{mg} / \mathrm{mL})\end{array}$ & $\mathrm{R}(\%)$ \\
\hline 30 & 550,27 & 1,86 & 507,51 & 10,15 \\
\hline 60 & 469,27 & 16,31 & 505,78 & 10,46 \\
\hline 90 & 444,94 & 20,65 & 513,08 & 9,17 \\
\hline 120 & 429,99 & 23,31 & 519,58 & 8,02 \\
\hline
\end{tabular}

[caseína $_{\text {controle }} \mathrm{LS} 0,05 \mathrm{M}=560,70(\mathrm{mg} / \mathrm{mL}) ;$ [caseína $_{\text {controle }}$ LS $0,1 \mathrm{M}=564,87(\mathrm{mg} / \mathrm{mL})$; *Solução em isooctano com $25 \mathrm{mM}$ de 1-hexanol

tém-se a melhor relação tempo/porcentagem de enzima extraída pelo sistema LS 0,05 M e 0,1 M (com 1-hexanol em isooctano), respectivamente.

A seguir, estudou-se a influência da concentração de 1-hexanol ( 0 ; 0,08 M; 0,22 M; 0,37 M e 0,74 M) empregando LS a $0,05 \mathrm{M}$ e $0,1 \mathrm{M}$, sobre a eficiência da extração da caseína.

Este estudo mostrou que para o sistema utilizando $0,05 \mathrm{M}$ de lecitina e $0,08 \mathrm{M}$ de 1 -hexanol ocorre uma diminuição no rendimento da etapa de extração que cai de $32 \%$ para $11 \%$, em comparação ao sistema sem 1-hexanol. No entanto, para LS 0,1 M com 0,08 M de 1-hexanol ocorre um aumento no rendimento da extração que sobe de $34 \%$ para $36 \%$, demonstrando existir uma relação entre a concentração do tensoativo e a concentração de co-solvente para o sistema.

Para concentrações superiores, $0,37 \mathrm{M}$ e $0,74 \mathrm{M}$ de 1-hexanol, empregando $0,05 \mathrm{M}$ de LS na composição do sistema os rendimentos de extração decrescem para $10 \% \mathrm{e}$ $2,5 \%$, respectivamente. Esta diminuição também foi observada empregando $0,1 \mathrm{M}$ de LS, para os quais os rendimentos de extração diminuíram para $10 \%$ e $0 \%$, utilizando 0,37 $\mathrm{M}$ e $0,74 \mathrm{M}$ de hexanol respectivamente.

Todos os experimentos anteriormente realizados sugeriram vários itens a serem modificados no processo de extração por micelas reversas de lecitina de soja (LS). O primeiro, e talvez o mais importante deles, o tipo de agitação empregada: nitidamente o vigor da agitação em vórtice promoveu a emulsificação do sistema comprometendo a separação das fases e impossibilitando a quantificação de proteínas e/ou atividades enzimáticas e segundo, o tamanho da proteína alvo (sua massa molar) tem significativa influência, ou seja, o sistema possui limitações na extração de proteínas de massa molar da ordem de $60 \mathrm{kDa}$.
Assim, para completar o estudo da influência dos fatores sobre o processo, procedeu-se à avaliação do $\mathrm{pH} \mathrm{e}$ da condutividade elétrica (salinidade).

Usou-se na formulação da fase aquosa inicial (contendo proteínas) os seguintes tampões: acetato de sódio $\mathrm{pH}$ 5,0, acetato de sódio $\mathrm{pH} 5,4$, e tris/ $\mathrm{HCl} \mathrm{pH}$ 7,9 nas seguintes concentrações: $0,05,0,1,0,25$ e $0,5 \mathrm{M}$.

Como proteína alvo, utilizou-se caseína e BSA, esta última para se confirmar a hipótese de exclusão por tamanho anteriormente defendida. No preparo do sistema micelar reverso empregou-se LS a 0,05 M e 0,1 M (com 1hexanol $25 \mathrm{~m} \mathrm{M}$ em isooctano).

Fixando o tempo de agitação em 60 minutos e utilizando o sistema micelar acima descrito, os ensaios foram conduzidos para averiguar a influência do $\mathrm{pH}$ e da força iônica sobre a etapa de extração de ambas as proteínas. Confirmando a hipótese de exclusão por tamanho da molécula de proteína, os rendimentos do processo de extração do BSA foram nulos, independentemente da condição empregada. No entanto, como mostra a Figura 1, os resultados foram positivos para extração da caseína (que possui menor massa molar) empregando as mesmas condições usadas nos experimentos com BSA.

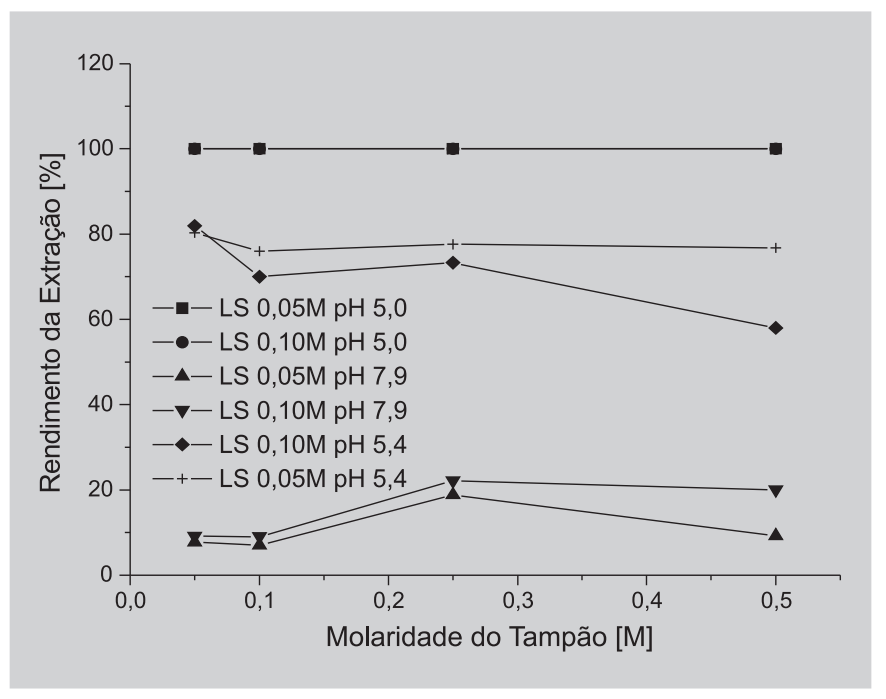

FIGURA 1 - Efeito do pH e força iônica na extração de caseína em sistema micelares reversos constituídos por LS/ isooctano/1-hexanol.

Conforme observado na Figura 1, os valores de rendimento de extração da proteína são muito influenciados pelo $\mathrm{pH}$ sendo que a máxima eficiência obtida foi de: $20 \%$ em pH 7,9, 80\% em pH 5,4 e 100\% em pH 5,0 (pH próximo ao $\mathrm{pI}$ da proteína). Estas porcentagens são relativas às proteínas presentes na fase aquosa inicial que foram englobadas pelas micelas reversas do sistema LS (com $25 \mathrm{mM}$ 
de 1-hexanol em isooctano) tanto para concentração de lecitina de $0,05 \mathrm{M}$ quanto para $0,1 \mathrm{M}$.

Desta forma, outro fator destacou-se como de extrema importância: as características de hidrofobicidade e hidrofilicidade das proteínas. Uma vez que no pI proteínas apresentam carga líquida nula, sob esta condição apresentarão baixa solubilidade aquosa, invertendo esta condição quando solubilizadas pelas micelas. Assim, os resultados de $100 \%$ de extração da caseína são justificados devido à utilização de $\mathrm{pH}$ próximo ao $\mathrm{pI}$ desta proteína.

\section{CONCLUSÕES}

O presente trabalho permitiu o desenvolvimento de um novo protocolo de execução do processo de extração de proteínas por micelas reversas. $\mathrm{O}$ sistema micelar reverso avaliado (LS em isooctano/1-hexanol) foi capaz de promover a extração de até $100 \%$ da caseína presente na solução inicial. Nos ensaios empregando-se BSA os resultados foram comprometidos devido a um marcante efeito de exclusão por tamanho desta molécula. O sistema não necessitou do uso do ligante $\mathrm{CB}$ para caseína, uma biomolécula cuja massa molar é compatível com o tamanho das micelas reversas formadas. A extração líquido-líquido de biomoléculas por micelas reversas de LS apresenta um inegável interesse ambiental e pode ser utilizada na extração de moléculas que estejam presentes em meios complexos. Devido à seletividade resultante da manipulação dos parâmetros que influem na extração, é possível seu uso na separação de misturas e isolamento seletivo de proteínas.

\section{ABSTRACT}

\section{Soybean lecithin reversed micelles - an alternative for protein purification}

In this work, the effect of different parameters for extraction of casein and bovine serum albumin (BSA) were studied. Such proteins were extracted by soybean lecithin reversed micelles. BSA extraction was not effective, independent of the extraction conditions employed. Owing to its molar mass, the effect of exclusion by size was clearly observed. The casein extraction yield increased about 23fold as a function of agitation time. In other words, the increase occurred by using higher contact time between protein and reversed micelles. The use of hexanol as a cosolvent was effective, and increased casein extraction to $36 \%$. The extraction values were strongly influenced by $p H$, and the high extraction yield was obtained under the following conditions: $20 \%$ at $\mathrm{pH} 7.9,80 \%$ at $\mathrm{pH} 5.4 \mathrm{e}$ $100 \%$ at pH 5.0 (close to casein isoelectrical point).
UNITERMS: Reversed Micelles. Soybean Lecithin. Liquid-liquid extraction. Casein. Bovine Serum Albumin. Protein/purification.

\section{AGRADECIMENTOS}

Os autores agradecem ao apoio financeiro da FAPESP, CAPES e CNPq. F.A. HASMANN e D.B. GURPILHARES agradecem, ainda, à FAPESP pelas bolsas auxílios concedidas.

\section{REFERÊNCIAS}

ÇIFITÇI, M., BEYDEMIR, S., YILMAZ, H., ALTIKAT, S. Purification glucose-6-phophate dehydrogenase from Buffalo (Bubalus bubalis) erythrocytes and investigation of some kinetic properties. Protein Expres. Purif, v.5, p.159-168, 2003.

CORTEZ E. V., PESSOA JUNIOR, A. Xylanase and betaxylosidase separation by fractional precipitation. Process Biochem., v.35, n.3-4, p.277-283, 1999.

FURUSAKI, S., KISHI, K. Extraction of amino acids by reversed micelles. Chem. Eng. Jpn., v.23,p.91-93, 1990.

GUPTA, R. B.; HAN, C. J.; JOHNSTON, K. P. Recovery of proteins and amino acids from reverse micelles by dehydration with molecular sieves. Biotechnol. Bioeng., v.44, p.830-838, 1994.

HASMANN, F. A., PESSOA JUNIOR, A., ROBERTO, I. C. Optimization of $\mathrm{pH}$ and temperature for beta-xylosidase recovery by reversed micelles. Biotechol. Tech., v.13, p.239-242, 1999.

HASMANN, F. A., PESSOA JUNIOR, A., ROBERTO, I. C. Screening of variables in beta-xylosidase recovery using cetyl trimethyl ammonium bromide reversed micelles. Appl. Biochem. Biotech., v.91-93, p.719-728, 2001.

HASMANN, F. A, GURPILHARES, D. B., ROBERTO, I. C.; PESSOA-JUNIOR, A. Response surface methodology for the evaluation of glucose-6-phosphate dehydrogenase enrichment process by soybean lecithin reversed micelles. J. Chromatogr. B, v.847, p.262-266 2007.

HASMANN, F. A., CORTEZ, D. V., ROBERTO, I. C., PESSOA JUNIOR, A. Optimization of beta-xylosidase recovery by reversed micelles using response surface methodology. J. Biotechnol., v.6, p.153-160, 2003. 
HWANG K. J.; HWANG H. C. The purification of protein in cross-flow microfiltration of microbe/protein mixtures Sep. Purif. Technol., v. 51, n.3, p.416-423, 2006.

ICHIKAWA, S., SUGIURA, S., NAKAJIMA, M., SANO, Y., SEKI, M., FURUSAKI, S. Formation of biocompatible reversed micellar systems using phospholipids. Biochem. Eng. J., v.6, p.193-199, 2000.

KILIKIAN B. V., BASTAZIN M. R., MINAMI, N. M., GONÇALVES E. M. R., PESSOA JUNIOR, A. LiquidLiquid extraction by reversed micelles in biotechnological processes. Braz. J. Chem. Eng.; v.17, n.1, p.29-38, 2000.

LEODIDIS, E. B., HATTON, T. A. Amino acids in AOT reversed micelles. Determination of interfacial partition coefficients using the phase-transfer method, J. Chem. Phys., v.64, p.6400-6411, 1990.

LOWRY, O. H., ROSEBROUGH, N. J., FARR, A. L., RANDALL, R. J. Protein measurement with the Folinphenol-reagent, J. Biotechol., v. 193, p.265-275, 1959.

MORITA, S., NARITA, H., MATOBA, T., KITO, M. Synthesis of triacylglycerol by lipase in phosphatidylcholine reverse micellar system. J. Am. Oil Chem. Soc., v.61, p.1571-1574, 1984.

ÖZER N., BILGI C., ÖGÜS, H. I. Dog liver glucose-6phosphate dehydrogenase: purification and kinetic properties. Int. J. Biochem. Cell. B., v.34, p.253-262, 2002.

PINTO-SOUSA, A. M., CABRAL, J. M. S., AIRESBARROS, M. R. Stability of a Fusarium solani pisi recombinant cutinase in phosphatidylcholine reversed micelles. Biotechnol. Lett., v.18, n.56, p. 583-586, 1996.
PIRES, M. J., AIRES-BARROS, M. R., CABRAL, J. M. S. Liquid-Liquid extraction of protein with reversed micelles. Biotechnol. Progress, v.12, p.290-301, 1996.

RAUTENBACH, R.; ALBRECHT, R. Membrane processes. New York: John Wiley \& Sons, 1989. 470p.

RODRIGUES, E. M., MILAGRES, A. M. F., PESSOA JUNIOR, A. Selective recovery of xylanase from Penicillium janthinellum using BDBAC reversed micelles. Acta Biotechnol., v.19, p.157-161, 1999.

SMITH, E L., HILL, R. L., LEHMAN, I. R., LEFKOWITZ, R. J., HANDLER, P. H., WHITE, A. Principles of biochemistry: general aspects. 7. ed. New York: McGrawHill, 1993. p.112-115

SUN, Y., BAI, S., GU, I., TONG, X. -D., ICHIKAWA, S., FURUSAKI, S. Effect of hexano as a cosolvent on partitioning and mass transfer rate of protein extraction using reversed micelles of CB-modified lecithin. Biochem. Eng. J., v.3, p.9-16, 1999.

VANÇAN, S. Purificação de imunoglobulina $G$ a partir do plasma ou soro humano utilizando cromatografia de afinidade com ions metálicos imobilizados. Campinas, 1999. p.148. [Tese de Mestrado. Faculdade de Engenharia Química. Universidade Estadual de Campinas].

YÜREGIR, G. T., AKSOY, K., ARPACI, A., UNLUKURT, I., TULI, A. Studies on red cell gucose-6-phosphate dehydrogenase. Evaluation of reverence values. Ann. Clin. Biochem., v. 31, p. 50-55, 1994.

YURTOV, E.V., MURASHOVA, N.M. Phase equilibria and nonequilibrium structures in the sodium di-2-ethylhexyl phosphate-decane-water system. Colloid J., v.66, p. 629634, 2003.

Recebido para publicação em 18 de outubro de 2006. Aceito para publicação em 02 de agosto de 2007. 